\title{
MUDANÇAS NAS INTERAÇÕES SOCIAIS E MOBILIDADE NA EDUCAÇÃO COM A MEDIAÇÃO DAS TECNOLOGIAS DIGITAIS DE INFORMAÇÃO E COMUNICAÇÃO
}

\author{
CAMBIOS EN LA INTERACCIÓN SOCIAL Y LA MOVILIDAD EN \\ EDUCACIÓN CON MEDIACION DE TECNOLOGIAS DIGITALES DE \\ INFORMACION Y COMUNICACION
}

CHANGES IN SOCIAL INTERACTIONS AND MOBILITY IN EDUCATION WITH MEDIATION OF DIGITAL MEDIA

\author{
Erika GIACOMETTI-ROCHA ${ }^{1}$ \\ Daniel MILL ${ }^{2}$
}

RESUMO: As TDIC permitem um determinado modo de funcionamento das interações sociais, proporcionando diversidade de ambientes ou situações sociais. Nesses termos, como são os deslocamentos para acesso à informação? Além disso, quais recursos e possíveis formas de agrupamento ocorrem como estratégias de estudo? Nas interações comunicativas, a constituição dos espaços se vincula ao acesso à informação mútua permitida entre duas pessoas. Um "lugar", aqui, não é apenas um espaço físico delimitado por uma fronteira ou borda, mas um sistema de informações que permite aos sujeitos definirem as situações sociais. Portanto, pensar nas instituições de ensino, nas bibliotecas públicas e outros lugares adquire complexidade, particularmente na cibercultura. Esses eram os espaços físicos que antes determinavam como seria o fluxo da informação aos estudantes. A investigação abordou a questão por meio de pesquisa quali-quantitativa. Os resultados sugerem possibilidades de acesso à informação pelos adolescentes, não fosse a estrutura institucional hoje. Existe um desafio no sentido de que a maior mobilidade proporcionada pelas atuais TDIC está, por ora, limitada.

PALAVRAS-CHAVE: Tecnologias digitais de informação e comunicação (TDIC). Interações sociais. Mobilidade.

RESUMEN: El TDIC permite un modo de funcionamiento particular de las interacciones sociales, proporcionando diversidad de ambientes o situaciones sociales. En estos términos, al igual que los movimientos para el acceso a la información? Además, ¿qué recursos y las posibles formas de agrupación producen como estrategias de estudio? En las interacciones comunicativas, la creación de espacios está vinculada a acceder a la información recíproca permitido entre dos personas. Un "lugar" aquí no es sólo un espacio físico delimitado por un límite o borde, sino un sistema de información que permite a los individuos definen las situaciones sociales. Así que piensa en las instituciones educativas, bibliotecas públicas y otros lugares adquiere complejidad, particularmente en la cibercultura. Estos fueron los espacios físicos que determinaron previamente como sería el flujo de información a los estudiantes. La

${ }^{1}$ Doutoranda em Educação (PPGE) na Linha Educação, Cultura e Subjetividade pela UFSCar (2016). Email: erikagiacometti@gmail.com

${ }^{2}$ Departamento de Educação. Coordenador UAB - UFSCar. E-mail: mill.ufscar@gmail.com 
investigación se dirigió a la cuestión a través de la investigación cualitativa y cuantitativa. Los resultados sugieren posibilidades de acceso a la información por los adolescentes, no era la estructura institucional actual. Hay un desafío en el sentido de que el aumento de la movilidad ofrecida por la corriente TDIC es por ahora limitado.

PALABRAS CLAVE: Las tecnologías digitales de información y comunicación (TDIC). Las interacciones sociales. La movilidad.

ABSTRACT: The digital media allow a certain way of functioning of social interactions, providing diversity of environments or social situations. In these terms, what are the displacements for access to information? In addition, what resources and possible forms of grouping occur as study strategies? In communicative interactions, the constitution of the spaces is linked to the access to the mutual information allowed between two people. A "place" here is not just a physical space bounded by a border or border, but an information system that allows subjects to define social situations. Therefore, thinking about educational institutions, public libraries and other places acquires complexity in cyberculture. These were the physical spaces that previously determined what the flow of information would be like for students. Research has addressed the issue through qualitative-quantitative research. The results suggest possibilities of access to information by adolescents, were it not for the institutional structure today. There is a challenge in the sense that the greater mobility provided by the current digital media is, for the time being, limited.

KEYWORDS: Digital media. Social interactions. Mobility.

\section{Introdução}

No contexto da cultura digital, as tecnologias digitais de informação e comunicação (TDIC), móveis e híbridas, servem como ambientes de socialização. Segundo Belloni (2009), outra de suas funções é contribuir para compensar as desigualdades que tendem a afastar a escola dos jovens e dificultar que a instituição escolar cumpra efetivamente sua missão de formar o cidadão. Por esse ângulo, refletir as interações sociais nas práticas escolares dos adolescentes, constantemente bombardeados pelo conteúdo cibernético e mediados por TDIC, é fundamental. Entretanto, isso tem sido feito apenas numa perspectiva focalizando muito pouco as características TDIC mais usadas pela grande maioria dos estudantes. Seus dispositivos digitais recebem constantes inovações e melhorias orientadas pelo mercado e estão se tornando imprescindíveis a diversas de suas atividades diárias.

Num outro sentido, conforme afirma Lemos (2008, p. 90), a cibercultura, desde o seu aparecimento, trouxe questões ligadas ao espaço, de modo que é constatável, em 
muitos trabalhos, menção dessa cultura como cultura do ciberespaço, do espaço eletrônico. Pensadas como canais, as TDIC veiculadoras dessa cibercultura são, diversas vezes vistas como meros instrumentos coadjuvantes da mensagem; quando, na verdade, carregam características próprias e limitações, de tal modo a oferecer experiências sensoriais, psicológicas e sociais completamente diferentes, decorrente dessas características específicas. Assim, a análise da mobilidade do sujeito no espaço físico constitui fator que pode ser visto como resultante do ambiente proporcionado por cada tipo de TDIC. Acrescenta-se que, segundo Meyrowitz (1985), os meios de comunicação (ou mídias) mudam não só o sentido de lugar como também criam novos ambientes sociais. Pode ainda, de acordo com o autor, produzir hierarquias e constituir identidades de grupo, uma vez que as informações compartilhadas entre os membros são passíveis de ser mantidas em segredo frente a participantes de outro núcleo. O autor procura entender como as situações sociais se transformam por causa dos meios de comunicação e como isso modifica o comportamento social das pessoas.

Segundo o autor, há duas questões fundamentais: “(1) como as mudanças nos meios de comunicação podem mudar ambientes sociais, e (2) os efeitos que uma mudança em ambientes sociais pode ter sobre o comportamento das pessoas" (MEYROWITZ, 1985, p. 53). Para chegar a uma nova compreensão dos efeitos das mídias eletrônicas no comportamento social, o autor funde a perspectiva teoria da mídia e a do situacionismo ${ }^{3}$, que seria a exploração das maneiras como o comportamento é moldado em situações sociais. Nessa perspectiva, é fácil transpor o conceito para as TDIC. Elas permitem que um determinado modo de funcionamento das interações sociais seja estabelecido, proporcionando diversidade de ambientes.

O uso massivo das TDIC redefine situações sociais que se tornam ultrapassadas. O problema é como as mídias modificam o nosso dia-a-dia, segundo o autor. Esse será um dos focos da análise deste trabalho. Nesses termos, como são os deslocamentos para acesso à informação? Além disso, quais recursos têm sido usados e quais as possíveis formas de agrupamento têm ocorrido como estratégias de estudo? Foi possível, a partir

3 Situacionismo refere-se ao Interacionismo Simbólico desenvolvido por George Mead, da Escola de Chicago, em 1937. O Canadense Erving Goffman (1922-1983), também integrante da Escola de Chicago, sofreu grande influência da Escola de Palo Alto e aliou a pesquisa do Interacionismo Simbólico (Situacionismo) a várias abordagens como, por exemplo, a dramaturgia. Um dos principais livros que o autor escreveu foi $A$ representação do eu no cotidiano social, em 1959. O Situacionismo defende que as mudanças no comportamento social dependem do nível de informação e do conhecimento das pessoas (SOUSA, 2004). Meyrowitz foi um pioneiro dentro dos estudos do meio ao fazer a junção com o Situacionismo. Não confundir com o Internacional Situacionista, movimento revolucionário político e estético da França, cujo principal nome é Guy Débord. 
dessas questões, identificar algumas mudanças nas interações sociais entre adolescentes, a partir das alterações na mobilidade espacial proporcionada pelas TDIC, no âmbito das práticas escolares. Nas relações comunicativas, a constituição dos espaços se vincula ao acesso à informação mútua permitida entre duas pessoas. Um "lugar", na perspectiva de Meyrowitz (1985), não é apenas um espaço físico delimitado por uma fronteira ou borda, mas um sistema de informações que permite aos sujeitos definirem as situações sociais.

Portanto, pensar nas instituições de ensino, nas bibliotecas públicas e outros lugares adquire complexidade, particularmente na cibercultura. Esses eram os espaços físicos que antes determinavam como seria o fluxo da informação aos estudantes. Com as TDIC, essa configuração de fluxo passa a ser outra. Os meios de comunicação modificam as situações sociais e comportamentos, porque alteram o sentido de lugar e nosso acesso aos sistemas de informação. Se antes as situações eram geralmente definidas por sua localização física, atualmente os meios de comunicação eletrônicos mudaram essa concepção.

Em perspectiva sociocultural, os meios de comunicação exercem controle sobre o modo como os indivíduos se comportam, porque suas características delimitam o funcionamento do ambiente social (MEYROWITZ, 1985, p. 34). Isso significa dizer que a informação que circula é modificada conforme os ambientes sociais criados. Para o autor, situações são frequentemente definidas em termos de comportamento em locais físicos, aquilo que é chamado pelo autor de situações sociais. Meyrowitz afirma ainda que "um dado local, como uma sala, toma um particular significado social porque paredes, portas e localização tendem a incluir e excluir participantes de um determinado modo" (MEYROWITZ, 1985, p. 35). Ao mesmo tempo, essas situações sociais são definidas por ele como sistemas de informação, no sentido de que se trata de informações sociais: "Todas as pessoas são capazes de saber o comportamento e ações delas mesmas e dos outros" (MEYROWITZ, 1985, p. 37). Em outras palavras, ele explica que cada lugar é uma situação social, porque possui um conjunto de códigos de comportamento, vestimenta, linguagem e discurso próprios, que são apreendidos pelos sujeitos ao longo das experiências de interações sociais. É nessa lógica que vê esses códigos como sistemas de informação. O sistema de informação de que tratamos, nesta pesquisa, é o conjunto de códigos usados pelos estudantes e professores para a construção do conhecimento: acesso ao saber escolar, comportamento e interação após terem como recursos adicionais as TDIC, de forma intensiva. 
Se a informação é um elemento fundamental para dizer ao indivíduo qual é seu lugar na sociedade, no momento em que esses controles são radicalmente alterados, essa perspectiva tende a se transformar ou mesmo desaparecer. Por isso, as mudanças do acesso à Internet e as mudanças de uso dos diferentes tipos de TDIC podem ser importantes para o processo de construção do conhecimento, já que o facilita. Ousa-se, aqui, pensar que essas mudanças podem gerar maior autonomia no sentido de que adolescentes dependem menos do espaço físico e, com o tempo, tendem a depender cada vez menos de um professor presencialmente disponível, conforme as estruturas institucionais tradicionalmente seguidas pela educação brasileira.

\section{Caminhos metodológicos}

Este trabalho é fruto de uma investigação de natureza descritiva, que abordou a questão observada por meio de pesquisa quali-quantitativa e foi devidamente submetida aos procedimentos do Comitê de Ética, tendo sido autorizada. O estudo buscou caracterizar algumas transformações postas aos sujeitos investigados, levando em conta a influência da presença de tecnologias digitais de informação e comunicação entre os participantes.

Como instrumentos para levantamento de dados, foram adotados questionários e entrevistas. O questionário, embora estruturado e objetivo, apresentou algumas questões com opção para o sujeito investigado comentar/registrar suas opiniões sobre certos assuntos. Destes comentários, extraíram-se dados analisados neste artigo. Para garantir maior amostragem, os questionários foram aplicados em material impresso. Posteriormente, os dados foram sistematizados em banco de dados digital. Para sistematização e análise dos dados recolhidos, adotamos as ferramentas do Access ${ }^{\circledR}$ e Excel®.

O questionário foi aplicado a 760 adolescentes, sendo aproveitadas as respostas de 533 participantes. A aplicação ocorreu em três escolas da rede privada e em três escolas da rede pública. Após organizar e sistematizar quadros, tabelas e figuras, dados textuais de entrevistas e comentários livres/abertos foram elaborados e analisados. O processo de sistematização dos dados em categorias de análise envolveu a observação de regularidades e padrões (BOGDAN; BLIKEN, 1994, p. 125).

Os sujeitos participantes da pesquisa tinham de 14 a 16 anos de idade. Os 
sujeitos de 14 anos somaram $146(27,4 \%)$ da amostra, os de 15 anos contabilizam 199 $(37,33 \%)$ e os de 16 anos, 188 (35,27\%). Em relação ao tipo de escola, observa-se que $385(72 \%)$ estudantes eram de escolas públicas e, para escolas privadas, eram 148 (28\%) sujeitos participantes estudantes de escolas privadas. Quanto ao aspecto sociocultural, os dados associados ao tipo de escola serão interessantes para entendermos as posições sociais dos sujeitos no contexto em que ocorrem os fatos observados na pesquisa, em algumas análises.

Levando-se em consideração que os costumes e a cultura relacionados à Internet no Brasil se manifestam também nas pesquisas nacionais, houve a preocupação em evidenciar os dados mostrando a intensidade de acesso à Internet. A intensidade de uso da Internet corresponde ao número de horas de acesso diário. Os dados de Almeida (2014) mostram que o tempo médio de acesso à Internet entre todos os estados é de 3 horas 39 minutos por dia.

Os dados recolhidos na coleta sobre o tempo de acesso determinaram os Grupos A e B: os que usam intensamente a Internet e os que não usam. Após determinar a marca de 3 horas diárias de acesso como marco estabelecido para o limite em que se inicia "uso Intensivo da Internet" nesta pesquisa, foram estabelecidos os grupos acima.

\section{Usos da TDIC e seus reflexos na mobilidade física e virtual: alguns dados}

Meyrowitz nos lembra de que, antes das mídias eletrônicas, não notávamos os lugares físicos como representantes dos lugares sociais. Quando se fala sobre esses lugares físicos, logo se pensa na ideia de que cada um possui seu próprio sistema de informação determinando interações sociais e comportamento. Era bem delimitado. Por isso, o autor enfatiza que, após as mídias eletrônicas, essa barreira desaparece e, portanto, passamos a nos preocupar com os limites desses sistemas. Além disso, Meyrowitz acrescenta que a evolução das mídias começou a encobrir a diferença entre um estranho e um amigo e enfraquecem a distinção entre pessoas que estão "aqui" e pessoas que estão "em algum outro lugar” (MEYROWITZ, 1985). Para a análise das mudanças de barreiras nas interações sociais e mobilidade entre adolescentes que usam intensivamente a Internet, começaremos pela descrição da atual condição de acesso dos adolescentes. 


\section{Frequência dos lugares onde adolescentes acessam a Internet}

No espaço escolar, de onde foram coletados os dados, os adolescentes têm duas possibilidades de acesso à Internet: o laboratório de informática do programa ProInfo6, e os seus dispositivos móveis, sejam eles, tablets, notebooks, netbooks, mas principalmente os celulares com Internet. Estes últimos têm classificação de alta mobilidade entre os dispositivos e não são usualmente considerados nos programas escolares como recurso didático. Sua vantagem é pronto acesso, caso haja conexão disponível e atualmente disponíveis são o sistema de $3^{\text {a }}$ geração, para quem paga planos a operadoras de Internet para celulares. Algumas delas disponibilizam acesso em plano pré-pago, mas o uso de dados é bem limitado. O acesso não chega a mais do que cinco páginas e roda com dificuldade um vídeo online. No entanto, os adolescentes conseguem trocar diversas mensagens nas redes sociais, embora não possam trocar muitos arquivos e nem abrir muitas fotos, por conta dessa limitação de dados das operadoras. Entre as formas de comunicação, além das redes sociais, os adolescentes têm o Whatsapp Messenger. Este aplicativo permite mensagens instantâneas e chamadas de voz para smartphones. Além de mensagens de texto, os usuários podem enviar imagens, vídeos e documentos em PDF, além de fazer ligações grátis por meio de uma conexão com a internet. É a forma de comunicação mais estável se há algum tipo de acesso.

$\mathrm{Na}$ escola, a banda larga é disponibilizada apenas para os computadores do prédio, entre eles os do laboratório de informática dos alunos. Nas escolas visitadas, o acesso no horário de intervalo é permitido. Portanto, por não haver acesso wi-fi permitido pelas instituições escolares, os adolescentes acessam em aula, nesse contexto acima descrito. Para além da conexão, o uso dos celulares serve para ver horas, calcular e mais um sem número de funções oferecidas por aplicativos disponíveis no mercado, sendo centenas deles distribuídos gratuitamente. Lembrando que, em aula, há ainda, professores que fazem valer a lei de proibição dos celulares em aula.

Entre os dados sobre mobilidade, procurou-se enfatizar as mudanças nas interações sociais e comportamento, no que se refere à busca de informações para o meio escolar. 
Figura 1: Distribuição dos grupos de participantes por acesso em TDIC e lugar.

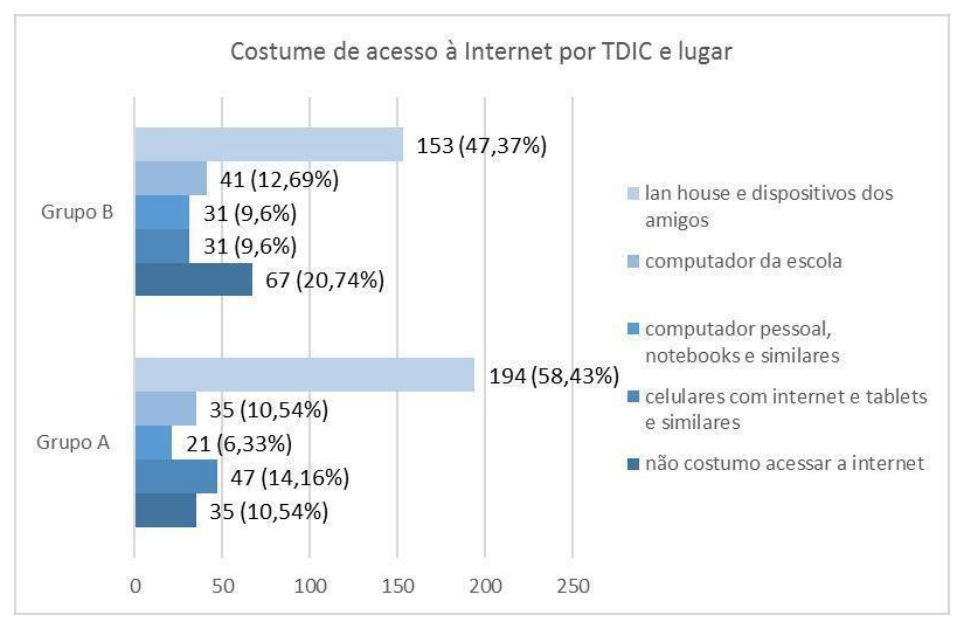

Fonte: elaboração própria

Esses dados sugerem que os grupos A e B, em maioria, costumam frequentar lan houses, assim como acessar a Internet em dispositivos de amigos, principalmente os que usam intensivamente a Internet (Grupo A), já que há mais respostas (58,43\%). Isso significa que há uma porcentagem expressiva de sujeitos que acessam intensivamente a Internet e que não integram o grupo daqueles supostamente com mais condições de comprar TDIC, não havendo relação, portanto, entre poder aquisitivo e poder de acesso. Os "computadores pessoais, notebooks e similares" são os menos acessados pelo grupo A. O grupo B acessa-os igualmente aos "celulares com Internet, tablets e celulares" em porcentagem menor entre as respostas. Sob o aspecto da mobilidade, enfatiza-se o considerável deslocamento para acesso de ambos os grupos, acentuadamente o grupo A.

A informação sobre o que eles acessam é para determinar se o conteúdo se refere ao conhecimento exigido pelas instituições escolares. O conteúdo da Internet, conforme acesso em "lan houses e em dispositivos de amigos" ocorre principalmente "para conversar com pessoas através de chats ou e-mail" $(33,14 \%)$ e em $2^{\circ}$ lugar entra "estudo ou pesquisa para trabalhos" (24,5\%).

No caso do acesso em "computador da escola ou em casa de amigos", foi bem menor o número de respostas, mas a ordem de acesso aos conteúdos e as proporções de respostas são semelhantes. Os dados sugerem que o acesso à Internet é, principalmente, para comunicação, mesmo nos computadores das escolas. Por outro lado, a diferença entre o primeiro e o segundo colocado só ocorre no caso do acesso em lan houses e casa de amigos, ficando uma diferença em cerca de 9 pontos contra 3 pontos percentuais quando o acesso é no computador da escola. 
Nesse caso, Barbosa (2014) afirma que a atividade que mais diferencia as práticas educativas dos alunos de escolas públicas de acordo com a idade são os jogos educativos. Essa é a segunda atividade mais comum entre os alunos do $5^{\circ}$ ano do Ensino Fundamental $(81 \%)$, ao passo que menos da metade dos alunos do $9^{\circ}$ ano do Ensino Fundamental e do $2^{\circ}$ ano do Ensino Médio (42\%) declaram ter realizado essa tarefa. O uso mais frequente desses recursos entre os alunos mais novos reflete as estratégias de aprendizagem consideradas mais apropriadas para essa faixa etária. No entanto, Barbosa afirma ainda que os jogos, mesmo sendo ferramentas bastante familiares aos estudantes, são oportunidades ainda pouco exploradas na educação, em particular em ferramentas como feedback das atividades em tempo real e vivência de diferentes papéis e experiências em um ambiente controlado (BARBOSA, 2014, p. 132).

Os dados sugerem haver potencial para exploração do ensino por meio de jogos, considerando que o uso por expressivo número de adolescentes do Ensino Médio é voltado para este fim, principalmente nos espaços das lan houses e na casa de amigos. Pensando em jogos educativos, as possibilidades ampliam-se, tendo em vista que muitos deles podem ser vinculados à Internet. Há um estudo de Carvalho, Haguenauer e Victorino (2005) que aponta a associação de Internet e jogos como ampliadores da representação da realidade, abrindo possibilidades para um novo enfoque educacional.

Assim, conclui-se que "as tecnologias móveis não fomentam apenas processos de desterritorialização, mas novas reterritorializações, através de dinâmicas de controle e acesso à informação" (LEMOS, 2007, p.02). Os dados sugerem que, na escola, o acesso é mais voltado para a comunicação, para o estudo e para o entretenimento, respectivamente, assim como em lan houses e em TDIC de amigos. Entretanto, o percentual de uso para o estudo, diminui de $27,63 \%$ na escola para $22,5 \%$ em lan houses e em TDIC de amigos. No caso, se pensarmos em desterritorialização e reterritorialização comentada por Lemos, temos que o acesso à informação de caráter escolar tende a ser deslocado para onde mais comumente as TDIC são usadas. Isso mostra a postura de destituição dos limites entre o espaço escolar e o de entretenimento, cujos lugares sociais são distintos, confirmando também o conceito de Meyrowitz (1985) sobre mudanças nas barreiras que ocasionam diferentes configurações em situações sociais.

\section{Recursos físicos versus recursos ciberespaciais: dados das preferências dos adolescentes}


O uso de recursos para estudar é fundamental à análise da mobilidade nos espaços físicos em relação aos tipos de TDIC. Quando se perguntou sobre bibliotecas, supôs-se que estas bibliotecas representariam as encontradas nas escolas. A biblioteca é um lugar onde encontramos tecnologias não digitais - os livros. No caso da Internet, pensou-se no acesso a quaisquer tipos de TDIC onde podemos acessar conteúdo semelhante aos livros. A figura 2 apresenta as respostas para a escolha dos recursos escolhidos pelos participantes da pesquisa:

Figura 2: Distribuição de participantes por uso de recurso para estudar.

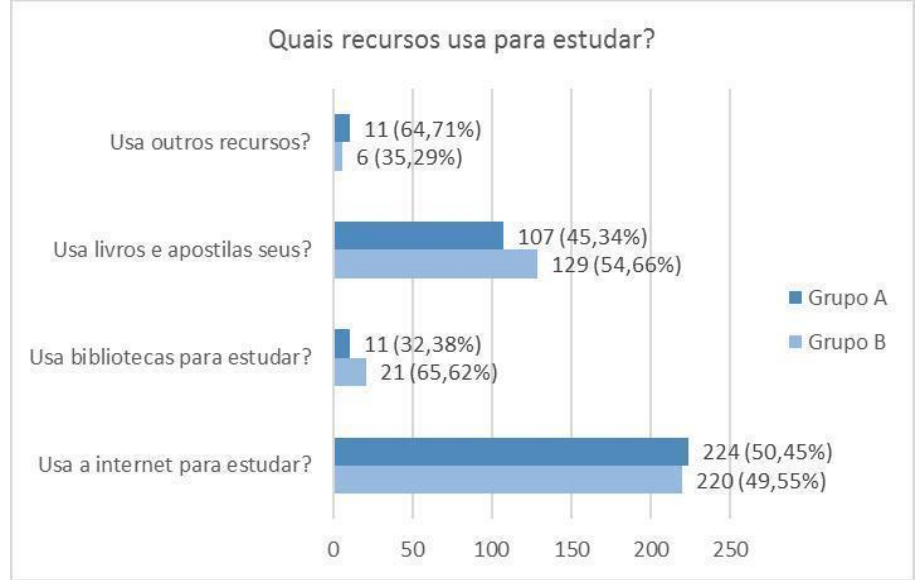

Fonte: Elaboração própria

Entre os recursos, o uso da Internet como fonte de pesquisa é o mais expressivo: $50,45 \%$ participantes do grupo A e 49,55\% do grupo B. O segundo recurso mais usado são os livros e apostilas dos próprios participantes (GA, com 45,34\% e GB, com $54,65 \%$ ). Como pode ser observado, quem usa menos a Internet, tende a usar mais livros e apostilas para estudar. Mas bibliotecas não são uma opção popular: na figura 2, a procura por bibliotecas é a mais baixa entre todas as escolhas por locais para estudar.

Os dados da figura 1 e 2 coadunam com os depoimentos coletados por MamedeNeves e Ribeiro, em que o grupo consultado elegeu a internet como espaço privilegiado de construção do conhecimento, de possibilidade de encontro, de entretenimento, de comunicação e lazer, pelas múltiplas possibilidades que oferece (MAMEDE-NEVES; RIBEIRO 2012, p. 235). Assim como neste trabalho, em Mamede-Neves e Ribeiro, os jovens e adolescentes tendem a considerar bastante prático o uso da Internet, inclusive porque concentra funções que satisfazem diversas necessidades ao mesmo tempo.

Acrescenta-se a Internet ser preferida pela "facilidade", "praticidade", "velocidade com que se extraem as informações", "praticidade", conforme relato dos 
participantes desta pesquisa. Entretanto, no resultado da figura 2, é preciso levar em conta dois fatores. Primeiramente, esses mesmos dados contrapõem-se a Mendes e Almeida (2011, p. 121), de modo geral, à medida que participantes declararam ainda frequentar a biblioteca para fazer leituras, apesar do uso de laptops na escola que facilita e torna as pesquisas mais rápidas e práticas. Podemos dizer que as declarações em Mendes e Almeida (2011) podem ser resultado de cultura local, se os resultados das declarações forem referentes a um grupo maior que a metade dos participantes daquela pesquisa.

A outra possibilidade é que as declarações podem ser pontuais e a tendência do grupo de uso de bibliotecas seria em proporção parecida à desta pesquisa. Caberia analisar os dados de Mendes e Almeida reproduzindo-os em metodologia semelhante. De qualquer forma, esta pesquisa apresenta a tendência à preferência pelo uso da Internet para estudo ou pesquisas, conforme aumenta a intensidade do uso diário de TDIC pelos participantes.

\section{Dados sobre agrupamento em escola, casa de amigos ou pela Internet}

Outro tipo de informação que foi recolhida relaciona-se às escolhas dos participantes em reunir-se para estudar em grupo. Este tipo de atividade usualmente era feito ou na escola ou na casa dos amigos. Com a Internet, passa a haver possibilidade de a reunião ser realizada pelos adolescentes em suas casas, através da comunicação partilhada por e-mail, webconferência ou outros recursos. Assim, os adolescentes foram questionados sobre quais eram os lugares que atualmente eles utilizam para realizar reuniões de estudo. Eles responderam em uma ordem de preferência, conforme a tabela que apresenta o número de respostas dos grupos A e B (GA e GB, respectivamente). 
Tabela 1: Preferência de lugar para reunião de estudo.

\begin{tabular}{|c|c|c|c|c|c|c|}
\hline \multirow{3}{*}{ Preferência } & \multicolumn{6}{|c|}{ (Valores apresentados por quantidade/\%) } \\
\hline & \multicolumn{2}{|c|}{ Na escola } & \multicolumn{2}{|c|}{$\begin{array}{l}\text { Na casa de um dos } \\
\text { integrantes }\end{array}$} & \multicolumn{2}{|c|}{ Via Internet } \\
\hline & GA & GB & GA & GB & GA & GB \\
\hline $1^{\circ}$ lugar & $81 / 33,47$ & $104 / 39,54$ & $93 / 40,97$ & $101 / 41,39$ & $56 / 24,24$ & $43 / 17,55$ \\
\hline $2^{\circ}$ lugar & $64 / 26,45$ & $70 / 26,62$ & $65 / 28,63$ & $80 / 32,79$ & $41 / 17,75$ & $43 / 17,55$ \\
\hline $3^{\circ}$ lugar & $53 / 21,90$ & $51 / 19,39$ & $36 / 15,86$ & $37 / 15,16$ & $78 / 33,77$ & 9337,96 \\
\hline Nunca & $44 / 18,18$ & $38 / 14,45$ & $33 / 14,54$ & $26 / 10,66$ & $56 / 24,24$ & $66 / 26,94$ \\
\hline $\begin{array}{l}\text { Total de } \\
\text { respostas }\end{array}$ & 242 & 263 & 227 & 244 & 231 & 245 \\
\hline \multicolumn{2}{|l|}{ Total da amostra } & 533 & & & & \\
\hline \multicolumn{2}{|c|}{ Total do Grupo A na amostra } & 257 & & & & \\
\hline \multicolumn{2}{|c|}{ Total do Grupo B na amostra } & 276 & & & & \\
\hline \multicolumn{2}{|c|}{ Abstenção de respostas } & 57 & & & & \\
\hline
\end{tabular}

Fonte: Elaboração própria

Os dados da tabela evidenciam uma aparente contradição. A maioria dos adolescentes de ambos os grupos escolheram em $1^{\circ}$ lugar a preferência por reunião em grupo na casa de amigos e depois a escola, ficando por último a escolha por reunião via Internet. Entretanto, quando se observa os dados referentes a cada grupo separadamente neste mesmo critério, o grupo A que acessa mais a Internet apresenta maior porcentagem de resposta $(24,24 \%)$ em relação ao grupo B $(17,55 \%)$. Segundo esses dados, os adolescentes que usam por mais tempo diário a Internet tendem a preferir a reunião via Internet. Ainda que essa pequena mudança possa não parecer significativa, há de se pensar na reflexão de Mamede-Neves e Ribeiro sobre as diferenças de opinião de professores sobre o uso da TDIC como instrumento didático: “[...]as considerações apontam para uma pluralidade própria de seu tempo de transição nas culturas. [...] há uma superposição de movimentos, linguagens que redundam em projetos nem sempre articulados, suscitando dilemas" (2012, p. 231). As autoras afirmam-no reforçando que o dilema é próprio das transformações, contudo não excluem potencialidades dos recursos (MAMEDES-NEVES; RIBEIRO, 2012, p. 232). Sugerem, portanto, que transformações demandam tempo. Esses alunos, que ainda resistem ao usar as TDIC para reunir-se em grupo com a finalidade de estudar, podem fazê-lo simplesmente porque as funcionalidades que permitem essa interação pela web não estejam sendo satisfatória. É possível pensar que nem todos os integrantes do grupo podem estar usufruindo de TDIC com as funcionalidades desejadas para uma webconferência. Os recursos precisam ser testados e amplamente usados até que cheguem à qualidade satisfatória (conforme apontamos no quadro 5) sobre a capacidade de navegação do 
browser em TDIC. Pode-se pensar ainda que existe uma preferência por se encontrarem presencialmente, em oposição à mediação das TDIC. Em caminho semelhante, Mamede-Neves e Ribeiro argumentam que os jovens consideram o ciberespaço, um “espaço de trocas formidável, sem que prescindam de sair para se divertir, nem que isso diminua os contatos presenciais” (MAMEDE-NEVES; RIBEIRO 2012, p. 236).

Numa outra perspectiva, as lan houses, conhecidamente usadas para usar chat e redes sociais e jogar games têm acesso expressivo modo geral. Isso representa potencial de uso para fins educacionais, pelo fato de haver um interesse grande em comunicar-se e jogar mediados pelas TDIC. Nesse aspecto, Barbosa (2014) afirma que a atividade que mais diferencia as práticas educativas dos alunos das escolas públicas de acordo com a idade são os jogos educativos. Essa é a segunda atividade mais comum entre os alunos do $5^{\circ}$ ano de ensino fundamental $(81 \%)$, ao passo que menos da metade dos alunos do $9^{\circ}$ ano e $2^{\circ}$ ano do ensino médio (42\%) declararam ter realizado essa tarefa. $\mathrm{O}$ uso mais frequente desses recursos entre os alunos mais novos reflete as estratégias de aprendizagem consideradas mais apropriadas para essa faixa etária. No entanto, Barbosa afirma ainda que os jogos, mesmo sendo ferramentas bastante familiares aos estudantes, são oportunidades ainda pouco exploradas na educação, em particular ferramentas como feedback das atividades em tempo real e a possibilidade de vivenciar diferentes papéis e experiências em um ambiente controlado (BARBOSA, 2014, p. 132). Acrescentamos que este potencial poderia ser mais explorado mesmo entre os jovens e adolescentes, bastando haver adequação à temática abordada, pois apesar de menor, há um grande grupo que expressa interesse em atividades tais como os jogos que proporcionam, em geral, desafios e recompensas. Portanto, além da questão da mobilidade e interações sociais específicas proporcionadas pelas TDIC, há a emergência da preferência por práticas educativas interativas relacionadas a essas tecnologias.

\section{Considerações}

Podemos pensar que os motivos são variados até porque a popularização desses recursos específicos de interação leva tempo para ser efetivada. Meyrowitz afirma que talvez uma das razões para que os teóricos tenham tendência para ver situações sociais como relativamente estáveis é que é extremamente haver uma mudança súbita generalizada em paredes, portas, o layout de uma cidade, ou em outras estruturas geográficas e arquitetônicas. Conforme exemplifica o autor, a mudança de situações e 
comportamentos pode ocorrer quando portas são abertas ou fechadas, paredes são construídas ou removidas ou com o apertar de um botão do microfone, o giro sobre de um aparelho de televisão, ou a resposta a um telefone (1986, p. 41).

Contudo, observar e interpretar essas mudanças quando existe uma tradição institucional muito forte não é tarefa fácil. Esse seria o caso das instituições escolares no Brasil. O funcionamento das estruturas que ainda remontam o século passado, senão séculos anteriores ainda faz parte das práticas pedagógicas. Nota-se em massa que o perfil dos estudantes mudou, que a presença de celulares em suas mãos multiplicou e os computadores estão aí servindo como instrumentos para construção dos saberes. Avaliar o impacto disso em termos de mudança cultural das práticas escolares dos adolescentes mostrou-se um desafio grande, porque os resultados não mostram diferenças significativas de práticas de estudo comparando aqueles que usam intensivamente a Internet e aqueles que usam. Estatisticamente, essa diferença não é suficiente para afirmar uma tendência de mudança. Ao mesmo tempo, nota-se, coincidentemente, que sempre em todos os dados, o grupo que usa intensivamente a Internet apresenta as porcentagens maiores, mesmo com mínima diferença. Ainda estatisticamente isso pode não representar muito, mas quando falamos em mudança cultural, principalmente quando há $n$ fatores de resistência às mudanças, essa mínima diferença persistente apresentada para o grupo que usa mais a Internet pode ser um ponto de partida em análises mais robustas do que a aqui realizada, em nível de mestrado. É nesse sentido que interpretamos os dados.

De uma forma geral, poderiam ser muito bem exploradas as possibilidades de acesso dos adolescentes à Internet, não fosse a estrutura institucional tal como ela é hoje. Existe um desafio no sentido de que a maior mobilidade proporcionada pelas atuais TDIC está, por ora, limitada. Mas os dados sugerem haver potencial para exploração do ensino por meio de jogos, considerando o número expressivo de adolescentes (72\%) do Ensino Médio presentes nos espaços das lan houses e na casa de amigos. Nota-se também que, embora os números percentuais do acesso à Internet em "Lan houses e TDIC de amigos" e do acesso "na escola" apresentem proximidade, claramente que os números absolutos são muito maiores para acesso em lan houses e TDIC de amigos e revelam a preferência pelo acesso nesses lugares. Eles usam esses espaços principalmente para comunicação, mas também para os estudos, ficando este critério de uso em $2^{\circ}$ lugar. 
Quando o assunto é fazer trabalhos em grupo, os alunos acabam preferindo reunir-se nas escolas e em segundo lugar fica a preferência pela casa de um dos integrantes. No primeiro caso, a escolha pode estar associada à praticidade de se resolver um problema já no ambiente onde se pode consultar os demais colegas e o professor para a realização da tarefa. No segundo caso, pode haver um componente de socialização e de conforto em questão. Um aprofundamento da questão seria necessário para saber as razões dessas escolhas, pois não foi comentado. Por outro lado, existe uma porcentagem ligeiramente maior de participantes que usam webconferências ou recursos similares para fazer trabalhos, à medida que usam a Internet por mais tempo diariamente. Apesar disso, a preferência geral por uso da Internet para reunião em grupo é muito menor do que a preferência por reunião na escola ou na casa de um dos integrantes do grupo.

Já quanto ao uso de recursos em geral, quase não usam bibliotecas, embora os que usem, o façam ocasionalmente. Para estudar, ainda preferem usar os livros e apostilas, principalmente entre os participantes do grupo que acessam menos tempo diário a Internet. Mas a pesquisa na Internet para estudo apresenta resultado bastante relevante para ambos os grupos, corroborando a opinião dos participantes que afirmam que a Internet é “prática”, "rápida”, “mais fácil” (etc.) do que outros recursos para o uso. Esses fatores são preponderantes para possibilitar autonomia na busca por conteúdos escolares no sentido de que a liberdade de escolher onde acessar a informação conforme opções viáveis e mais práticas. Contudo, essa autonomia é bastante limitada, pois os acessos à Internet são feitos em locais onde se necessita um alto grau de deslocamento para acontecer: lan houses e casa de amigos. Os celulares, que possibilitam baixa mobilidade espacial e, portanto, pronto uso, são menos usados.

A capacidade dos seus aparelhos ainda é muito limitada no uso dos dados fornecidos pelos pacotes de Internet e, nas escolas, não é permitido o acesso à Internet local. Se esses adolescentes, mesmo sendo um dos que acessam intensamente a Internet diariamente, ainda hoje prefiram reunir-se na escola ou na casa de um dos colegas para estudar, isso tende a mudar conforme as TDIC evoluam, fornecendo maior qualidade e comodidade nas webconferências ou recursos similares, tão logo essas melhorias se tornem mais reais e estáveis à experiência de interação. Ademais, existe potencial a ser explorado, pois há um grande grupo de adolescentes que frequentam lan houses e expressa interesse em atividades tais como os jogos. Esse quadro proporciona, em geral, desafios e recompensas, um dos princípios norteadores da criação de motivação para os 
estudos em qualquer disciplina regular. No mais, a exploração dos papéis desempenhados nesses ambientes, à medida em que há socialização em situações sociais distintas, proporcionam maiores possibilidades de aprendizagem e experiências socializadoras para o ensino e aprendizagem.

\section{Referências}

BARBOSA, V. F. A. (Coord.). Pesquisa sobre o uso das tecnologias de informação e comunicação nas escolas brasileiras: TIC Educação 2014. São Paulo: Comitê Gestor da Internet no Brasil, 2014. Disponível_em:<http://www.cetic.br/media/docs/publicacoes/2/TIC_Educacao_2014_li vro_eletronic o.pdf>. Acesso em: 20 ago. 2014.

CARVAlHO, F. S.; HAGUENAUER, C. J.; VICTORINO, A. L. Q. Utilização de jogos interativos no ensino a distância via internet. 2005. Disponível em: http://abed.org.br/congresso2005/por/pdf/040tcc5.pdf. Acesso em 06 jul. 2016.

LEMOS, A. Ciberespaço e tecnologias móveis: processos de territorialização e desterritorialização na cibercultura. Imagem, visibilidade e cultura midiática. Livro da XV COMPÓS. Porto Alegre: Sulina, 2007. Disponível em <http://www.facom.ufba.br/ciberpesquisa/andrelemos/territorio.pdf> Acesso em: 10 nov. 2015.

LEMOS, A. Mídia locativa e territórios informacionais. Information media, 2008. Disponível em: <http://www.facom.ufba.br/ciberpesquisa/andrelemos/midia_locativa.pdf> Acesso em: 10 nov. 2015.

MAMEDE-NEVES, M. A.; RIBEIRO, F. N. Jovens e mestres em rede. In: Cultura digital e escola: pesquisa e formação de professores. Papirus: São Paulo, 2012. p. 227 252.

MENDES, M.; ALMEIDA, M. E. B. Utilização do laptop educacional em sala de aula. O computador portátil na escola: mudanças e desafios nos processos de ensino e aprendizagem. São Paulo: Avercamp, 2011.

MEYROWITZ, J. No sense of place: the impact of electronic media on social behavior. London: Oxford University Press, 1985.

SOUSA, J. K. L. L. de. Segunda Geração da Teoria do Meio: a contribuição de Meyrowitz. In: IV Encontro dos Núcleos de Pesquisa da Intercom. Brasília, 2004. Disponível em:

http://www.portcom.intercom.org.br/pdfs/3098150556560837131807531575526253152 4.pdf> Acesso em: 10 jun. 2016. 


\section{Como referenciar este artigo:}

GIACOMETTI-ROCHA, Erika.; MILL, Daniel. Mudanças nas interações sociais e mobilidade na educação com a mediação das Tecnologias Digitais de Informação e Comunicação. Revista Ibero-Americana de Estudos em Educação, Araraquara, v. 12, n. 2, p. 966-982, 2017. Disponível em: <http://dx.doi.org/10.21723/riaee.v12.n2.9074>. E-ISSN: 1982-5587.

Submetido em: 11/05/2017

Aprovação final em: 30/05/2017 